\title{
Por uma pedagogia latino-americana
}

\author{
For latin american pedagogy
}

\begin{abstract}
Dulcineia Aparecida Ferraz Ribeiro ${ }^{1}$
Vanderlei Barbosa ${ }^{2}$
\end{abstract}

\section{Resumo}

O presente artigo tem como objetivo refletir sobre a possibilidade de uma pedagogia latino-americana, comprometida com uma visão de formação integral do ser humano abrangendo os aspectos: epistemológico, pedagógico, político, filosófico, ético, estético, teológico, ecológico, místico e utópico. Baseada nessa perspectiva, a questão que orientou esse trabalho foi: Que tipo de formação humana contribuirá na adoção de práticas educacionais emancipatórias? A partir dessa inquietação foi realizado um estudo teórico-bibliográfico, da obra de Paulo Freire, partindo do livro Pedagogia do Oprimido (1988), complementando com outras obras mais recentes que descrevem o pensamento de Paulo Freire na América Latina. A análise das ideias freireana evidenciou que formar integralmente significa ter uma percepção do sujeito no mundo, com o mundo e em interação com o outro, concretamente situado numa realidade de opressão. Foram estabelecidas as inferências por meio de análises e interpretações em busca de novas descobertas em que obtivemos como resultados, uma possibilidade de formação humana e sua conexão com a Pedagogia Latino-Americana, bem como o anúncio de outras perspectivas práticas educacionais emancipatórias para um futuro possível.

Palavras-chave: Pedagogia latino-americana. Utopia. Formação. Paulo Freire.

\begin{abstract}
This article aims to reflect on the possibility of a Latin American pedagogy, committed to a vision of integral formation of the human being, covering the following aspects: epistemological, pedagogical, political, philosophical, ethical, aesthetic, theological, ecological, mystical and utopian. Based on this perspective, the question that guided this work was: What kind of human formation will contribute to the adoption of emancipatory educational practices? Based on this concern, a theoretical and bibliographic study of Paulo Freire's work was carried out, starting from the book Pedagogia do Oprimido (1988), complementing with other more recent works that

\footnotetext{
${ }^{1}$ Mestre em Educação pela Universidade Federal de Lavras - UFLA. Nepomuceno/MG, Brasil. E-mail: dulcineianep@yahoo.com.br

2 Doutor em Filosofia, História e Educação pela Universidade Estadual de Campinas/UNICAMP. Professor de Filosofia da Educação da Universidade Federal de Lavras - UFLA. Professor do Programa de Pós-Graduação em Educação - PPGE/UFLA e Coordenador e pesquisador do Grupo de Pesquisa Movimento, sabedoria, ideias e comunhão - MOSAICO. Lavras/MG/Brasil. E-mail: vanderleibarbosa@ded.ufla.br
} 
describe Paulo Freire's thought in Latin America. The analysis of Freirean ideas showed that integral training means having a perception of the subject in the world, with the world and in interaction with the other, concretely situated in a reality of oppression. Inferences were established through analyzes and interpretations in search of new discoveries in which we obtained as a result, a possibility of human formation and its connection with Latin American Pedagogy, as well as the announcement of other emancipatory educational practical perspectives for a possible future .

Keywords: Latin American pedagogy. Utopia. Formation. Paulo Freire.

\section{Introdução}

Esse artigo teve como objetivo refletir sobre a possibilidade de uma pedagogia latino-americana, adotando a perspectiva freireana na formação integral do ser humano, em que possa contribuir com a práxis transformadora na educação.

A América Latina como território livre do atraso e do subdesenvolvimento foi sempre um ideal acalentado por muitos pensadores e líderes como Simon Bolívar, José de San Martín e dentre eles o educador brasileiro Paulo Freire, que por meio de suas principais obras: Educação como Prática da Liberdade (2018) e Pedagogia do Oprimido (1988), apresentam uma visão antropológica, centrada no ser humano que se encontra no mundo e com o outro, ambos inacabados, inconclusos e incompletos, numa realidade histórica de opressão que tem como base sua existência, em que os discursos fatalista e sectário estão presentes, na atualidade latino-americana.

As reflexões contidas no livro, Pedagogia do Oprimido de Paulo Freire rompem com o clima de silêncio, de apatia, de desesperança, de autoritarismo, de sectarismo e propõe um caminho autêntico da cidadania, partindo da realidade concreta dos excluídos. Essa será perpassada pela práxis do oprimido e da oprimida e de lideranças revolucionárias. Nesse sentido, é preciso reconhecer a importância da Pedagogia do Oprimido em termos mais globais e não somente em termos locais ${ }^{3}$, pois a pedagogia freireana não é só aplicável no chamado "Terceiro Mundo", mas sim corresponde a uma das mais importantes respostas descoloniais do conhecimento, do ser e do poder no contexto latino-americano.

${ }^{3}$ É o que defende Carlos Alberto Torres, professor da Universidade da Califórnia, Los Angeles, um dos principais estudiosos de Paulo Freire. (TORRES, 1996: 567-568; apud GADOTTI, 2018, p.9). 
Baseada nessa perspectiva, de que a Pedagogia do Oprimido oferece uma possibilidade de formação emancipatória e segundo Lourenzo Luzuariaga (1959) "nos ensina que a Pedagogia cria os fins e os métodos de Educação, organiza-lhes as instituições e, depois, a política nada cria; apenas facilita aquilo que os pensadores e pedagogos inventam (...)" (LUZURIAGA, 1959; apud GADOTTI, 2018, p. 307), surge então, a questão que orientou esse trabalho: Que tipo de formação humana contribuirá para práxis educativa emancipatória? Para responder essa questão mostraremos a educação como instrumento de libertação política e social, como também pontuaremos uma educação comprometida com a formação integral do ser humano e como contribuição para a práxis libertadora, sendo um aspecto importante na atualidade.

Considerando isso, as informações foram estabelecidas por inferências e por meio da interpretação, na busca permanente de novas descobertas. O resultado dessa reflexão sobre a formação humana e sua conexão com a Pedagogia Latino Americana, nos apresenta uma visão do fenômeno educativo num espaço mais abrangente que o da escola, sem desconsiderá-la e o anúncio da possibilidade de desenvolver a educação integral favorecendo a continuidade à história crítica e pedagógica do pensamento de Freire.

Desse modo, no primeiro momento, o artigo faz uma interconexão da Pedagogia latino-americana com as ideias freireana, com a corroboração de José Pedro Boufleuer (1991), que faz a articulação da Pedagogia da Libertação de Paulo Freire com a Filosofia de Libertação de Enrique Dussel, dentro do contexto histórico-social, onde se luta por direitos, por liberdade de "ser mais", ou seja, uma luta por humanização e a importância da Pedagogia do Oprimido na atualidade. Em seguida, apresenta de forma sintética a formação humana integral na perspectiva freireana, que anuncia uma visão de sujeito integrado na história, assumindo a sua palavra, sua voz, mas não a voz do outro, a voz com o outro, como sujeito dialógico. E, finalmente, apresentamos, de forma articulada as diferentes dimensões de formação humana integral, que contribuirão para uma educação emancipatória na busca de romper com a educação sectária, fatalista e reacionária.

\section{Educação: compromisso ético-político}


Paulo Freire, no campo da pedagogia, é considerado um grande expoente latinoamericano do século XX. Tinha uma fé radical na capacidade dos oprimidos e das oprimidas de se reinventarem e de melhorarem o mundo. Indignado com as injustiças sociais, lutou de forma esperançosa e lançou-se ao mundo e não desistiu de anunciar uma educação libertadora, como processo de formação da consciência, permeada nos diferentes espaços latino-americanos. Isso continua, até hoje, sendo referência e desafio para reinventar novas práticas de educação.

Além disso, Paulo Freire lutou contra a dominação, contra a opressão humana de classe, de raça e de gênero em nosso continente, lutou também por uma pedagogia que tem sua razão dentro do contexto histórico-social, onde se luta por direitos, por liberdade de "ser mais", ou seja, uma luta por humanização dentro do sistema educacional dos países capitalista. Corrobora com esta perspectiva a obra Pedagogia Latino-Americana/Freire e Dussel (1991), de José Pedro Boufleuer, que faz a articulação da Pedagogia da Libertação de Paulo Freire com a Filosofia de Libertação de Enrique Dussel, ambos situados na América Latina.

Segundo Boufleuer, o ser humano latino não era visto como um ser, com o "outro", e sim um ser para o outro. Assim, Freire e Dussel, estavam preocupados com a dignidade e a libertação do ser humano oprimido, que se justifica em razão de ser dentro de um contexto onde a liberdade é negada. Por isso, brotam as propostas da Pedagogia Libertadora, ou Pedagogia Latino-Americana, que assume os desafios de seu mundo e transforma-o criativamente.

Ora, as características específicas da realidade latina americana, tanto para Freire e quanto para Dussel, partem daquilo que o próprio oprimido é o agente histórico da sua libertação. Esse trabalho politicamente pedagógico precisa ser realizado num clima de interação comunicativa, com ambos (opressor e oprimido) e, a partir dessa filosofia educacional o objetivo é instaurar uma autêntica práxis educacional, tendo em vista a educação emancipadora ${ }^{4}$.

Repensar essas questões no contexto da América Latina, em países em desenvolvimento, requer escolha e decisão política, mobilização e organização para a luta, por isso, a escola não pode ser um lugar neutro, pois é nela que o pensamento, a

\footnotetext{
${ }^{4}$ Cf. Pedagogia Latino-Americana/Freire e Dussel (1991), de José Pedro Boufleuer, que faz a articulação com a contribuição de "racionalidade comunicativa" proposta por Habermas.
} 
consciência crítica se desenvolvem para transformar a realidade. Esse processo de conscientização é provido pela educação, que passa a ser um instrumento de libertação política e social, que vai à contramão da história.

Com essas ideias a pedagogia de Paulo Freire anuncia o diálogo, a esperança, o amor, como formas de resistência e de liberdade, contra a lógica da guerra e do ódio. Nesse sentido, suas ideias mantêm-se atuais e necessárias para eliminar o sistema opressor presentes nas sociedades desiguais. Os desafios dessa educação como instrumento de transformação social não violenta, contribuir para a mudança no mundo, humanizando-o, transformando as relações autoritárias de poder por relações éticas. Formar o ser humano numa dimensão integral supõe abrir caminhos para um modelo libertador de educação, que reflita sobre o poder e suas causas a partir das suas várias vertentes. É o que passaremos a apresentar, de forma sintética.

\section{Formação Integral: dimensões do ser humano e do conhecimento}

A formação integral na perspectiva da pedagogia latino-americana anuncia uma visão do ser humano como sujeito integrado na história, assumindo a sua palavra, sujeito de voz, mas não a voz do outro, mas a voz com o outro, um sujeito dialógico. Com essa afirmação são anunciados os aspectos: epistemológico, pedagógico, político, filosófico, ético, estético, teológico, ecológico, místico, utópico. Nesse sentido mais específico as diferentes dimensões devem compartilhar entre si o sentido de refletir sobre a formação integral.

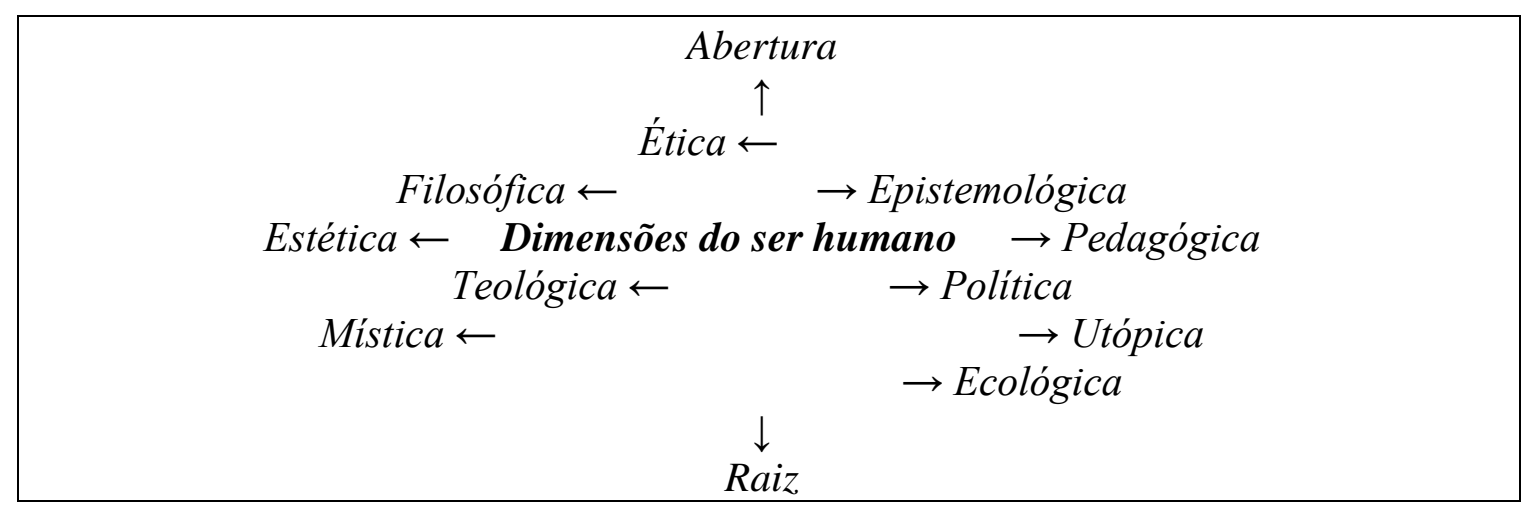

Fonte: tabela criada pelos autores. 
Referindo a Dimensão epistemológica, segundo Fernando Becker (2016), o conceito de epistemologia freireana é a origem do conhecimento que se constrói de forma crítica, nas relações do ser humano no mundo, com o mundo e com as pessoas. [...] "conhecer é tarefa de sujeitos, não de objetos. E é como sujeito e somente, enquanto sujeito, que o homem pode realmente conhecer" (FREIRE, 1977, p. 27 apud BECKER, 2016, p.152)

Ser sujeito significa estar integrado ao seu contexto, encarando diferentes desafios de forma dialógica, consciente, livre e criativa. No entanto, a educação problematizadora, envolve relações dialógicas, a partir da realidade e o pensar autêntico. Um sujeito ativo para questionar e duvidar. Essa a capacidade de perguntar é que torna a pessoa livre, como também desenvolve a consciência crítica. Essa forma de educar problematizando possibilita superar a alienação, compreender e intervir sobre a realidade para, então, modificá-la. Criando, recriando e participando como sujeito do seu tempo histórico, uma nova visão de ser humano e de educação.

$\mathrm{Na}$ objetivação transparece, pois, a responsabilidade histórica do sujeito: ao reproduzi-la criticamente, o homem se reconhece como sujeito que elabora o mundo; nele, no mundo, efetua-se a necessária mediação do auto reconhecimento que o personaliza e o conscientiza como autor responsável de sua própria história. $\mathrm{O}$ mundo conscientiza-se como projeto humano: o homem faz-se livre. $\mathrm{O}$ que pareceria ser apenas visão, é, efetivamente, "provocação"; o espetáculo, em verdade, é compromisso. (FREIRE, 1988, p.17)

Dessa forma, a construção do mundo é, acima de tudo, um processo de conhecimento crítico. O sentido de esperança, de otimismo, de responsabilidade vai proporcionando novos projetos e planos, que atingem a consciência e é transformador. A educação como prática da liberdade passa a ser uma força instrumental para a compreensão da realidade na sua totalidade, num processo de conscientização do ser humano sobre os riscos do seu tempo, colocando-o em convicção de que participa das mudanças na sociedade como ser da práxis, não apenas da prática.

A práxis gera uma dimensão dialógica e ética, o reconhecimento do outro, no mundo e com o mundo, que tem o direito de aprender a dizer a sua palavra.

Com a palavra, o homem se faz homem. Ao dizer a sua palavra, pois, o homem assume conscientemente sua essencial condição humana. $\mathrm{E}$ o método que lhe propicia essa aprendizagem comensura-se ao homem todo, e seus princípios fundam toda pedagogia, desde a 
alfabetização até os mais altos níveis do labor universitário. (FREIRE, 1988, p.13)

Acreditar no educando como sujeito de poder fazer, discutir e trabalhar pela sua realidade local e global, significa que educar é um ato de amor e de coragem.

Considerando a dimensão pedagógica, essa dimensão supera as posturas que se realizam na educação "bancária”, educador-educandos ambos os sujeitos do conhecimento e não separam a ideia de ensinar-aprender-pesquisar.

Se, na educação como situação gnosiológica, o ato cognoscente do sujeito educador (também educando) sobre o objeto cognoscível, não morre, ou nele se esgota, porque, dialogicamente, se estende a outros sujeitos cognoscentes, de tal maneira que o objeto cognoscível se faz mediador da cognoscibilidade dos dois, na teoria da ação revolucionária se dá o mesmo. Isto é, a liderança tem, nos oprimidos, sujeitos também da ação libertadora e, na realidade, a mediação da ação transformadora de ambos. Nesta teoria da ação, exatamente porque é revolucionária, não é possível falar nem em ator, no singular, nem apenas em atores, no plural, mas em atores em intersubjetividade, em intercomunicação. (FREIRE, 1988, p.125)

Essa concepção pedagógica que se realiza como situação gnosiológica é um processo dialético-problematizador, ou seja, partem de uma leitura crítica da realidade e do ser humano concreto, esses em processo de construção e em constante transformação. Essa categoria que explica que a realidade não é determinada e acabada é uma ideia central para um projeto pedagógico crítico, propositivo, esperançoso em relação ao futuro.

A educação libertadora, problematizadora possibilita o ser humano oprimido, marginalizado na busca de "ser mais". Esse conceito freireano, traz a ideia de que tanto o educando como o educador, buscam esse sentido de humanização, nas relações dialógicas e problematizadoras, sendo um grande desafio da educação.

Na dimensão política, de acordo com as experiências de Freire, a educação é uma forma de intervenção no mundo, que pode ser tanto de reprodução como de transformação. A primeira atende a lógica do mercado, da rentabilidade e do lucro, vai para dentro da escola que se reduz a mero repetidor da realidade consumista. A segunda terá que partir do contexto histórico, ir mais além dessa realidade de opressão. Ir além significa ter consciência política dessa realidade, para denunciar essa profunda desigualdade econômica e social. 
Não é possível desenvolvimento de sociedades duais, reflexas, invadidas, dependentes da sociedade metropolitana, pois que são sociedades alienadas, cujo ponto de decisão política, econômica e cultural se encontra fora delas - na sociedade metropolitana. Esta é que decide dos destinos, em última análise, daquelas, que apenas se transformam. Como "seres para outro", a sua transformação interessa precisamente à metrópole. (FREIRE, 1988, p. 159)

Por tudo isso, a educação como transformação é um ato político e também, opção, escolha e decisão pelas classes populares, pelos oprimidos, pelos que estão a margem, como possibilidade de uma vida de equidade para todos/as e não somente para um tipo de classe social.

Essa forma de pensar a dignidade humana será feito com os pensamentos poéticos do educador Rubem Alves (1988):

Não basta que os pobres tenham pão. É necessário que o pão seja
comido com alegria, nos jardins. Não basta que as portas das prisões
sejam abertas. É necessário que haja música nas ruas. Política, no final
das contas, não será simplesmente isto, a arte da jardinagem
transplantada para as coisas sociais? (...) É preciso reaprender a
linguagem do amor, das coisas belas e das coisas boas, para que o
corpo se levante e disponha a lutar. Porque o corpo não luta pela
verdade pura, mas está sempre pronto a viver e morrer pelas coisas
que ele ama. (ALVES, 1988, p.105)

Essa coragem do enfrentamento colocada por essa dimensão política nos convida a sermos também corajosos para construção de um mundo mais justo, equilibrado, tolerante e que valoriza a diversidade.

Na dimensão filosófica, Freire mostra sua linha teórica existencial, por ser capaz de se distanciar da realidade presente, concreta e por estar sendo no mundo sistematizou a filosofia da educação, dialogou com as obras de "Georg Wilhelm Friedrich Hegel, Karl Marx, Friederich Engels, György Lukács, Erich Fromm, Herbert Marcuse, entre outros", como afirmam Agostini e Silveira (2018 p.157).

Dentre essas ideias coexistem as categorias de origem Cristã, como a ideia de diálogo, e influências marxistas, como a noção de classe (GADOTTI, 2018). Essa forma de diálogo como processo dialético-problematizador faz com que seja vista a realidade concreta de forma inacabada e em constante transformação. Além disso, segundo Henz (2016), Freire foi influenciado pelos existencialistas: Emmanuel Mounier, Gabriel Marcel, Merleau-Ponty, Jean-Paul Sartre, Pierre Teilhard de Chardin e outros, para a 
valorização e a defesa da pessoa contra toda forma de opressão, de autoritarismo e/ou de alienação, principalmente, no contexto da América Latina.

O conceito de antropologia para Freire segundo Henz (2016), "concebe o gênero humano como o único dentre as espécies vivas, que não tem seu modus vivendi já estabelecido ao nascer. A natureza dos seres humanos é vir-à-ser, é construção e conquista permanente, busca incessante e progressiva, própria do inacabamento e condicionamento sócio histórico de homens e mulheres, que estão sendo num mundo e numa história também em construção e re-construção" (HENZ, 2016, p.44).

Esse pressuposto antropológico considera o ser humano como sujeito de sua história, interagindo com o outro e com o mundo, integrando seu passado e seu presente para transformar seu futuro, resultante da práxis permanente das pessoas e sobre a realidade como processo emancipatório.

As duas dimensões ética e estética dialogam-se como forma de resistir às condições sociais e econômicas de opressão e dominação. Educar para transformar a ética do mercado, em que propaga uma visão fatalista e determinista, para ética universal do ser humano, em que proporciona um mundo melhor para todas as pessoas, principalmente, para aquelas que são vítimas de injustiças, que é fonte geradora de uma falsa generosidade, essa, como instrumento de opressão, para manterem a miséria e a desumanização. Somente o oprimido que vive na pele essa terrível opressão é que poderá lutar pela restauração da sua humanidade.

Dessa forma, o/a educador/a que é o/a profissional do ser humano, além de ter responsabilidade, compromisso político, competência, tem que ter esse olhar ético e estético com atitudes de repensar a forma de educar para trabalhar as relações humanas e criar um ambiente bonito, belo, proporcionando o despertar da curiosidade, para o desejo de aprender, de construir valores e atitudes, de ciência, de cidadania, enfim, para apreender a realidade, de forma crítica e criativa transformando-a onde seja menos difícil de amar.

Acerca da dimensão teológica, Freire (1988) combate a falsa visão de Deus, a partir da problematização e do diálogo em torno de crenças construídas pela realidade opressora. Assim, pode chegar a uma conscientização, que possibilitará à autêntica libertação dos seres humanos, tendo assim um compromisso com a transformação dos mitos, um exemplo, de que Deus é o responsável por todas as situações vivenciadas. A 
presença do mito permaneceria assim, imutável, por toda sua existência, com a presença da ideia fatalista "A educação problematizadora, que não é fixismo reacionária, é futuridade revolucionária.” (FREIRE, 1988, p.73)

Freire (1988) vê a importância da conscientização para denunciar a realidade desumana e anunciar que é possível mudar, onde o ser humano possa "ser mais". Tinha uma visão, de que o ser humano é um ser transcendente e tem consciência de sua finitude, de sua incompletude e uma ligação com seu Criador. Daí que a religião (religare), que encarna este sentido transcendental das relações do ser humano com seu Criador, jamais deva ser um instrumento de sua alienação.

Segundo Nilo Agostini (2019), a vida e a obra de Freire vêm de encontro com o pensamento Cristão. Suas leituras se baseavam nos pensadores franceses: Jacques Maritain, Georges Bernamos, Emmanuel Mounier e outros, que defendiam um cristianismo social e uma visão personalista integral e no pensador brasileiro Alceu Amoroso Lima (Tristão de Ataíde) como interlocutor no Brasil. Foram nos Movimentos de Educação de Base (MEB) da Igreja Católica, que Freire se integrou ao projeto, que tinha como proposta a participação consciente do povo no desenvolvimento do país, partindo da perspectiva do/a oprimido/a.

De acordo com Leonardo Boff (2016), "a referência a essa dimensão cristã não é irrelevante, pois constituía a fé pessoal de Paulo Freire. O cristianismo inaugurou a transdescendência: o transcendente desceu na forma de pobreza e humildade, na imanência. Daí irrompeu a transparência que é a transcendência e a imanência se interpenetrando mutuamente. É a suprema realização do humano”. (BOFF, 2016, p.408)

Educação como instrumento de libertação mergulhada nas relações humanas e nas relações transcendentais como forma de abrir as consciências para uma visão mais crítica do que seja revolução da realidade, em que vigora a justiça social.

A dimensão mística nas ideias freireanas é determinante, quando sua presença no mundo, com o mundo e com as pessoas, principalmente com o oprimido era o que lhe fazia dar sentido à vida. Acreditava que para chegar à transcendentalidade precisava partir da vivência com as pessoas, principalmente, com as pessoas que estavam à margem do processo histórico-social-econômico-político. Acreditava que seu papel não era só de constatar o que acontecia na realidade, como algo imutável “(...) que sua 
situação concreta não é destino certo ou vontade de Deus (FREIRE, 1988, p.89)”, mas como sujeito da transformação desse mundo.

Considerando a dimensão ecológica foi um dos últimos textos escritos por Paulo Freire, no livro póstumo, intitulado Pedagogia da Indignação: cartas pedagógicas e outros escritos, organizado por Ana Maria Araújo Freire. Desvela uma grande missão de lutar pelo respeito à vida como forma de amar o mundo com a humanidade. Podemos inferir que estava muito atento a essa discussão ao defender o território latino-americano como lócus da libertação, incluindo os excluídos, as condições materiais de vida e de sobrevivência de uma sociedade de empobrecidos. Como pensador das questões humanas, ele via na percepção integradora, o meio ambiente como uma condição necessária de cuidado e de reverência.

A noção de dimensão utópica freireana expressa à superação das situaçõeslimites, num processo contínuo e coletivo de projetar, de agir sobre um novo horizonte. Além disso, contribui para a formação de educadores/as em suas práxis transformadoras, diante do cenário atual.

Esta é a razão pela qual não são as "situações limites", em si mesmas geradoras de um clima de desesperança, mas a percepção que os homens tenham delas num dado momento histórico, como um freio a eles, como algo que eles não podem ultrapassar. No momento em que a percepção critica se instaura, na ação mesma, se desenvolve um clima de esperança e confiança que leva os homens a empenhar-se na superação das "situações-limites". (FREIRE, 1988, p.91)

Freire (1988) coloca que a utopia mobiliza a esperança, apesar de a desesperança existir num dado momento histórico, não poderá ficar parados na pura espera. A percepção crítica (conscientização) é que dará possibilidade para o “inédito viável". Portanto, a dimensão utópica nos convida a superar as situações-limites e chegar ao inédito viável, através da práxis transformadora, da educação crítica, da curiosidade epistemológica, da escuta, do diálogo e acima de tudo, da amorosidade.

Essas dimensões acima sintetizadas, que dialogam entre si sobre a formação integral do ser humano têm por objetivo redefinir o papel dos/as educadores/as, dos/as educando/as, dos currículos, da pedagogia como práxis transformadora da realidade, ou seja, desenvolver a capacidade de agir e intervir para mudar o futuro.

\section{Considerações finais}

Revista Devir Educação, Lavras-MG. Edição Especial - Ago./2020. 
As ideias de Paulo Freire, principalmente a obra Pedagogia do Oprimido são imprescindíveis, porque apresentam uma "visão de homem" pluralista e comprometida com a mudança da realidade. Décadas depois de suas obras seminais serem escritas, vemos a necessidade de revisitá-las, certos da atualidade de suas ideias como fundamentos para pensar nas possibilidades de um fazer pedagógico libertário, partindo da formação integral do ser humano. Paulo Freire é leitura obrigatória para todos/as que continuam sonhando e lutando por uma pedagogia latino-americana.

Como vimos, a formação integral potencializa variadas e interdependentes dimensões e se iniciam com a dimensão ética que traz como reflexão a sensibilidade diante das injustiças sociais e a luta feita pelos injustiçados, com a mediação dos líderes revolucionários. Essa formação ética se integra e se articula com as outras dimensões: epistemológica, pedagógica, filosófica, política, ética e estética, teológica, mística, utópica, que colocam no centro do problema a questão do poder, propiciando a possibilidade do ser humano, ser sujeito de voz, que reconhece o outro na sua subjetividade de saberes e de cultura e que seja capaz de refazer o caminho, incluindo o cuidado com o planeta Terra, onde todos/as possam viver melhor, essa é o desafio que traz a dimensão ecológica.

A partir disso, a formação humana integral passa a ser libertadora, contribui para desenvolver o ser humano, como sujeito construtor da história individual e coletiva de forma dialógica e reflexiva. Esperamos que essas reflexões possam nos nutrir de esperanças e colaborar para discussões coletivas, que causem consciência crítica e transformação, ainda que só um pedacinho: um inédito viável.

\section{Referências}

AGOSTINI, Nilo. Os desafios da educação a partir de Paulo Freire e Walter

Benjamin. Editora Vozes, 2019.

AGOSTINI, Nilo; SILVEIRA, Carlos Roberto. A educação segundo Paulo Freire: da participação à libertação. Reflexão e Ação. Santa Cruz do Sul, vol.26, n. 1, jan.abr./2018, p.149-164.

ALVES, Rubem. Estórias de quem gosta de ensinar. 16 ed. - São Paulo: Cortez 1988. 


\section{OO DEVIR EDUCAÇÃO \\ ISSN: 2526-849X}

BARBOSA, Vanderlei. Da Ética da Libertação à Ética do Cuidado: uma leitura a partir do pensamento de Leonardo Boff. São Paulo: Porto de Ideias, 2009.

BOFF, Leonardo. In. Dicionário Paulo Freire. Belo Horizonte: Autêntica, 2016.

BOUFLEUER, José Pedro. Pedagogia latino-americana: Freire e Dussel. Ijuí: Unijuí Ed.,1991.

FREIRE, Paulo. Educação como prática da liberdade. 42a . ed. Rio de Janeiro/ São Paulo: Paz e Terra, 2018.

FREIRE, Paulo. Pedagogia da esperança: um reencontro com a pedagogia do oprimido. $4^{\text {a }}$. ed. Rio de Janeiro / São Paulo: Paz e Terra, 2011.

FREIRE, Paulo. Pedagogia da indignação: cartas pedagógicas e outros escritos. São Paulo: UNESP, 2000.

FREIRE, Paulo. Pedagogia do oprimido. 13. Ed. Rio de Janeiro: Paz \&Terra, 1988. GADOTTI, Moacir, CARNOY, Martin (org.) Reinventando Freire: a práxis do Instituto Paulo Freire. São Paulo: IPF, Lemann Center, Stanford Graduate School of Education, 2018.

GADOTTI, Moacir. Pedagogia do Oprimido como Pedagogia da Autonomia e da Esperança. São Paulo, 2018.

HENZ, Celso Ilgo. "Presencia (en el mundo)". In. Dicionário Paulo Freire. Belo Horizonte: Autêntica, 2016.

NOËL, Jean-Christophe. “Justiça/Justiça Social”. In. Dicionário Paulo Freire. Belo Horizonte: Autêntica, 2016.

REDIN, Euclides. “Alegria”. In. Dicionário Paulo Freire. Belo Horizonte: Autêntica, 2016.

ROSSATO, Ricardo. “Paciência/Impaciência”. In. Dicionário Paulo Freire. Belo Horizonte: Autêntica, 2016.

TROMBETTA, Sergio; TROMBETTA, Luís Carlos "Inacabamento". In. Dicionário Paulo Freire. Belo Horizonte: Autêntica, 2016.

ZITKOSKI, Jaime José. “Pensar Corretamente”. In. Dicionário Paulo Freire. Belo Horizonte: Autêntica, 2016. 